\title{
Evaluation of pesticide residues in commercial Swiss beeswax collected in 2019 using ultra-high performance liquid chromatographic analysis
}

\author{
Joshua N. G. Marti ${ }^{1}$. Verena Kilchenmann ${ }^{1} \cdot$ Christina Kast $^{1}$ (1)
}

Received: 28 September 2021 / Accepted: 23 December 2021 / Published online: 11 January 2022

(c) The Author(s) 2022

\begin{abstract}
The aim of this study was to determine residue levels of pesticides in Swiss commercial beeswax. Foundation samples were collected in 2019 from nine commercial manufacturers for analysis of 21 pesticides using ultra-high performance liquid chromatography. Individual samples showed the variability and residue ranges and pooled samples represented the average annual residue values of the Swiss production. In total, 17 pesticides were identified and 13 pesticides were quantified. They included 13 acaricides and/or insecticides, two fungicides as well as a synergist and a repellent. The means calculated from individual samples were similar to the average annual residue values for most tested pesticides. Mean values of 401, 236, 106 and $3 \mu \mathrm{g} \cdot \mathrm{kg}^{-1}$ were obtained for the beekeeping-associated contaminants coumaphos, tau-fluvalinate, bromopropylate and $\mathrm{N}$-(2,4-Dimethylphenyl)-formamide (DMF; breakdown product of amitraz), respectively. For the other pesticides, the mean values were $203 \mu \mathrm{g} \cdot \mathrm{kg}^{-1}$ (synergist piperonyl butoxide), $120 \mu \mathrm{g} \cdot \mathrm{kg}^{-1}$ (repellent $N, N$-Diethyl-3-methylbenzamide, DEET), $19 \mu \mathrm{g} \cdot \mathrm{kg}^{-1}$ (chlorfenvinphos) and $4 \mu \mathrm{g} \cdot \mathrm{kg}^{-1}$ ((E)-fenpyroximate), while the means for acrinathrin, azoxystrobin, bendiocarb, boscalid, chlorpyrifos, flumethrin, permethrin, propoxur and thiacloprid were below the limit of quantification $(<L O Q)$. Individual samples contained from seven to 14 pesticides. The ranges of values for coumaphos and piperonyl butoxide (from 14 to $4270 \mu \mathrm{g} \cdot \mathrm{kg}^{-1}$; from 6 to $1555 \mu \mathrm{g} \cdot \mathrm{kg}^{-1}$, respectively) were larger as compared to the ranges of values for DEET and tau-fluvalinate (from $<L O Q$ to $585 \mu \mathrm{g} \cdot \mathrm{kg}^{-1}$; from 16 to $572 \mu \mathrm{g} \cdot \mathrm{kg}^{-1}$, respectively). In conclusion, the most prominent contaminants were the pesticides coumaphos and tau-fluvalinate, which are both acaricides with previous authorization for beekeeping in Switzerland, followed by piperonyl butoxide, a synergist to enhance the effect of insecticides.
\end{abstract}

Keywords Apis mellifera $\cdot$ Beeswax $\cdot$ Varroa destructor $\cdot$ Acaricide $\cdot$ Pesticide $\cdot$ Residue

\section{Introduction}

Honeybees (Apis mellifera) play an important role as pollinators in ecosystems and agriculture. However, many studies report colonies losses due to various reasons, including beekeeping practice, honey bee diseases, especially the mite Varroa destructor and its associated viruses, and exposure to pesticides (Rosenkranz et al. 2010; Steinhauer et al. 2018). When beekeepers use veterinary drugs to treat mite infestation, these substances can accumulate in the beehive.

Responsible Editor: Ester Heath

Christina Kast

christina.kast@agroscope.admin.ch

1 Agroscope, Swiss Bee Research Centre, Schwarzenburgstrasse 161, 3003 Bern, Switzerland
In beeswax, lipophilic acaricides are the most frequently detected pesticides at the highest levels (Bogdanov 2004; Boi et al. 2016; Calatayud-Vernich et al. 2017; Chauzat et al. 2011; El Agrebi et al. 2020; Fulton et al. 2019; Wallner 1999) probably related to the fact that they are directly applied into the hive. Plant-protecting products used in agriculture are an additional source of pesticide residues in beeswax. Bees may bring these pesticides into the colonies when they forage for pollen and nectar. Thus, honey bees can be exposed to a variety of pesticides. Hydrophilic substances with a low logarithmic octanol-water partition coefficient tend to accumulate in honey, while lipophilic pesticides with a high logarithmic octanol-water partition coefficient preferentially accumulate in beeswax (Murcia Morales et al. 2020). The accumulation of pesticides in beeswax is especially critical, since the highly sensitive honeybee larvae are exposed to these pesticides through direct contact to the beeswax or 
indirectly if the pesticides migrate from the beeswax into the larval jelly (Kast and Kilchenmann 2022; Wilmart et al. 2021).

In good beekeeping practice, the brood combs are replaced after three to four years. The old comb wax is recycled by melting the combs together with capping wax in water vapour producing blocks for the manufacturing of new foundation sheets. Beekeepers place frames containing these new foundations in the hives for the bees to construct new combs. Many pesticides remain in the recycled wax and are still present in the newly produced wax foundation sheets (Bogdanov et al. 1998; Martel et al. 2007). Even years after a product is no longer used, residues of the active ingredients can be measured in beeswax (Kast et al. 2021), thus constantly exposing the bees to pesticides and possibly affecting honeybee health (Kast and Kilchenmann 2022; Wu et al. 2011).

Recent studies reported multiple pesticide residues in European beeswax (El Agrebi et al. 2020; Martinello et al. 2020; Perugini et al. 2018; Shimshoni et al. 2019). In Switzerland, the three beekeeping-associated acaricides coumaphos, tau-fluvalinate and bromopropylate have been monitored for three decades using gas chromatography (Kast et al. 2021). So far, there is no recent data on additional pesticide residues, including pesticides related to agricultural use. Therefore, an alternative method based on liquid chromatography was validated with the aim to compare residue levels in Swiss beeswax to the levels in beeswax of other countries.

First, 98 individual foundation samples were analysed to obtain the prevalence of a given pesticide alongside the range. Analysis of individual batches/samples gives a good idea of the variability and the maximal residue levels that customers can expect when buying foundation sheets. In a second step, samples were pooled according to the weight of each production batch, which led to results that came as close as possible to an overall average value for the annual production of Switzerland. These data can serve as a baseline for comparison with future residue levels.

\section{Material and methods}

\section{Material}

Caffeine (Art. C0750), acrinathrin (PESTANAL, Art. 46415), coumaphos (PESTANAL, Art. 45403), chlorpyrifos (PESTANAL, Art. 45395), flupyradifurone (PESTANAL, Art. 37050) and thiacloprid (PESTANAL, Art. 37905) were purchased from Sigma-Aldrich (Seelze, Germany). Azoxystrobin (Art. C10413000), bendiocarb (Art. C10460000), boscalid (Art. C10663000), bromopropylate (Art. C10762000), chlorfenvinphos (Art. C11290000),
$N, N$-Diethyl-3-methylbenzamide (DEET, Art. C12100000), deltamethrin (Art. C12120000), $N$-(2,4-Dimethylphenyl)formamide (DMF, Art. C12737000), fenitrothion (Art. C13480000), (E)-fenpyroximate (Art. C13545000), flumethrin (Art. C13719000), tau-fluvaliante (Art. C13870000), permethrin (Art. C15990000), piperonyl butoxide (Art. C16240000), propoxur (Art. C16500000) and zeta-cypermethrin (Art. C11890500) were obtained from Dr Ehrenstorfer (Augsburg, Germany). Acetonitrile of SupraSolv quality and 2-propanol of LiChrosolv quality were purchased from Merck (Darmstadt, Germany). Formic acid solution 50\% (Art. 09676) was obtained from Honeywell Fluka (Buchs, Switzerland). Ammonium formate (Art. 70221) was purchased from Supelco (Darmstadt, Germany). Bondesil PSA $40 \mu \mathrm{m}$ (Art. 12213024) and Bondesil C18 $40 \mu \mathrm{m}$ (Art. 12213012) were obtained from Agilent Technologies (USA). Syringe filters $0.45 \mu \mathrm{m}$ polyamide (Art. 729049) were purchased from Machery-Nagel (Düren, Germany). The water used for the mobile phases was purified with a Milli-Q IQ 7000 system.

\section{Beeswax for blank wax extracts}

Before the study was started, analysis was performed on wax blocks from three organic apiaries to find a suitable beeswax that can be used as blank wax extract. The beeswax that was chosen was from newly constructed combs produced in the year 2012, since it contained the lowest overall level of pesticide residues. Nevertheless, it contained DEET at approximately $20 \mu \mathrm{g} \cdot \mathrm{kg}^{-1}$ and azoxystrobin at approximately $7 \mu \mathrm{g} \cdot \mathrm{kg}^{-1}$.

\section{Beeswax samples from the manufacturers of foundations}

This study on pesticide residues in commercial beeswax included all major commercial manufacturers in Switzerland. Each of the nine participating manufacturers produced between 400 and $28000 \mathrm{~kg}$ of foundations sheets during the year 2019. Wax samples were collected all year long from each produced batch and stored in the dark at $-20{ }^{\circ} \mathrm{C}$. At the beginning of the year 2020, all the manufacturers sent their samples (321 samples in total) to the Swiss Bee Research Centre together with the information on the size of each productions batch. The number of samples/batches per producer ranged from 3 to 171 . For single batch analysis, approximately every third batch was sampled (for each manufacturer: 43 out of $171 ; 13$ out of $49 ; 8$ out of $31 ; 7$ out of $27 ; 6$ out of $21 ; 8$ out of $8 ; 7$ out of $7 ; 4$ out of $4 ; 2$ out of 3 samples), which led to an even distribution across the year and was more or less in proportion to the production volume of each manufacturer. In total, 98 out of 321 samples ( $31 \%$ of all samples) were analysed individually. In addition, 
representative samples were prepared for each manufacturer by combining wax from each sample/batch in proportion to the corresponding size of the production batch (Kast et al. 2021). Pooled samples have been previously analysed by gas chromatography (Kast et al. 2021). The pooled samples of the year 2019 were reanalysed in this study using the newly validated method based on liquid chromatography to obtain the annual residue values of 18 additional pesticides. From the annual residue values of the nine manufacturers, the average annual value of the residues for all Switzerland (later named annual value) was calculated. To obtain an annual value as close as possible to a true average value for Switzerland, the different amounts of foundations produced by each manufacturer during the year were taken into account. Values $<L O Q$ were replaced with zero for the calculation.

\section{Sample preparation}

The extraction procedure for all the tested pesticides was performed according to a modified QuEChERS (quick, easy, cheap, efficient, rugged, safe) method, which is based on a procedure previously described by Kast et al. (2020). Wax $(0.48-0.52 \mathrm{~g})$ was weighed into a $50 \mathrm{~mL}$ centrifugation tube and the exact mass was noted for later correction of the initial weight. Acetonitrile $(5 \mathrm{~mL})$ containing caffeine at $50 \mu \mathrm{g} / \mathrm{L}$ were added. The sample was placed in a hot water bath at $80^{\circ} \mathrm{C}$ for $30 \mathrm{~min}$ to melt the wax. Subsequently, the sample was shaken vigorously by hand for $30 \mathrm{~s}$ and placed back in the hot water bath for another $10 \mathrm{~min}$. This step was repeated three more times before the sample was placed at $80{ }^{\circ} \mathrm{C}$ for a final $10 \mathrm{~min}$. Then the sample was allowed to cool to room temperature. Subsequently, the sample was placed at $-20^{\circ} \mathrm{C}$ overnight, followed by centrifugation at $10000 \mathrm{~g}$ at $4{ }^{\circ} \mathrm{C}$ for $20 \mathrm{~min}$ on the next day. After the centrifugation step, $1 \mathrm{~mL}$ of the supernatant was pipetted into a $1.5 \mathrm{~mL}$ Eppendorf tube containing $25 \mathrm{mg}$ PSA and $25 \mathrm{mg}$ C18. The tube was mixed twice on the vortex stirrer for $30 \mathrm{~s}$. Afterwards, the tube was stored in the freezer at $-20{ }^{\circ} \mathrm{C}$ overnight. The sample was then separated by centrifugation at $18000 \mathrm{~g}$ at $4{ }^{\circ} \mathrm{C}$ for $20 \mathrm{~min}$. Finally, the supernatant was filtered through a $0.45 \mu \mathrm{m}$ polyamide membrane into an auto sampler vial.

\section{UHPLC-MS/MS analysis}

Three individual methods (A, B and C) were established for the analysis of the 21 pesticides with variable eluent gradients and ion source conditions of the mass spectrometer (MS). Method A allowed analysis of fenitrothion, chlorpyrifos, zeta-cypermethrin, deltamethrin, acrinathrin, permethrin and flumethrin. Method B was used for the analysis of DMF (the principal breakdown product of amitraz in wax foundations; Calatayud-Vernich et al. 2017), coumaphos, bromopropylate and $t a u$-fluvalinate, and method $\mathrm{C}$ for flupyradifurone, thiacloprid, propoxur, bendiocarb, DEET, azoxystrobin, boscalid, chlorfenvinphos, piperonyl butoxide and (E)-fenpyroximate.

Ultra-high performance liquid chromatography (UHPLC) analysis was performed on an Agilent 1290 Infinity II system equipped with an auto sampler and coupled to an Agilent $6495 \mathrm{C}$ mass spectrometer (MS). For separation, a $\mathrm{C} 18$ reversed phase column (Acquity UPLC HSS T3 column, $100 \AA, 1.8 \mu \mathrm{m}, 2.1 \mathrm{~mm} \times 100 \mathrm{~mm}$; Waters) was used. The column temperature was $40{ }^{\circ} \mathrm{C}$. The mobile phase A was $95 \%$ water $+5 \%$ acetonitrile $+0.01 \%$ formic acid $+5 \mathrm{mM}$ ammonium formate and the mobile phase B was $5 \%$ water $+95 \%$ acetonitrile $+0.01 \%$ formic acid $+5 \mathrm{mM}$ ammonium formate. Three individual gradients for methods $\mathrm{A}, \mathrm{B}$ and $\mathrm{C}$ were used for the separation of the pesticides. The conditions of the gradients are listed in Table 1. The flow rate was $0.5 \mathrm{ml}$ per min, and 2-propanol, acetonitrile and $0.01 \%$ formic acid in water were used to wash the needle. The temperature of the autosampler was $10{ }^{\circ} \mathrm{C}$ and the injection volume was $1 \mu \mathrm{L}$. An Agilent $6495 \mathrm{C}$ series tandem quadrupole MS system equipped with an electrospray ionisation source was used for detection of the various pesticides using mass fragmentation. The ion source conditions using positive mode electrospray ionisation for methods A, B and C are listed in Table 2, and the ion transitions for the pesticides are listed in Table 3. For each compound, one transition was used for quantification and two additional transitions for identification.
Table 1 LC-gradients for methods A, B and C

\begin{tabular}{|c|c|c|c|c|c|c|c|c|c|}
\hline \multirow[b]{2}{*}{ Step } & \multicolumn{3}{|l|}{ Method A } & \multicolumn{3}{|l|}{ Method B } & \multicolumn{3}{|l|}{ Method C } \\
\hline & Time $^{\mathrm{a}}$ & $A^{b}$ & $\mathrm{~B}^{\mathrm{c}}$ & Time & A & B & Time & A & B \\
\hline 1 & $0.25 \mathrm{~min}$ & $100 \%$ & $0 \%$ & $0.25 \mathrm{~min}$ & $100 \%$ & $0 \%$ & $0.25 \mathrm{~min}$ & $100 \%$ & $0 \%$ \\
\hline 2 & $6.60 \mathrm{~min}$ & $20 \%$ & $80 \%$ & $6.60 \mathrm{~min}$ & $0 \%$ & $100 \%$ & $4.00 \mathrm{~min}$ & $60 \%$ & $40 \%$ \\
\hline 3 & $13.00 \mathrm{~min}$ & $0 \%$ & $100 \%$ & $12.00 \mathrm{~min}$ & $0 \%$ & $100 \%$ & $6.60 \mathrm{~min}$ & $0 \%$ & $100 \%$ \\
\hline 4 & $13.01 \mathrm{~min}$ & $100 \%$ & $0 \%$ & $12.01 \mathrm{~min}$ & $100 \%$ & $0 \%$ & $9.01 \mathrm{~min}$ & $100 \%$ & $0 \%$ \\
\hline
\end{tabular}

${ }^{\mathrm{a}}$ Time indicates the time at which the indicated ratio of $\mathrm{A} / \mathrm{B}$ is present

${ }^{\mathrm{b}}$ Mobile phase A: $95 \%$ water $+5 \%$ acetonitrile $+0.01 \%$ formic acid $+5 \mathrm{mM}$ ammonium formate

${ }^{\mathrm{c}}$ Mobile phase B: $5 \%$ water $+95 \%$ acetonitrile $+0.01 \%$ formic acid $+5 \mathrm{mM}$ ammonium formate 
Table 2 Ion source conditions of methods A, Band C

\begin{tabular}{llll}
\hline Method & A & B & C \\
\hline Gas temp $\left({ }^{\circ} \mathrm{C}\right)$ & 130 & 180 & 250 \\
Gas flow $(\mathrm{L} / \mathrm{min})$ & 20 & 20 & 20 \\
Nebulizer $(\mathrm{psi})$ & 30 & 30 & 60 \\
SheathGasHeater $\left({ }^{\circ} \mathrm{C}\right)$ & 120 & 150 & 320 \\
SheathGasFlow $(\mathrm{L} / \mathrm{min})$ & 10 & 6 & 10 \\
Capillary $(\mathrm{V})$ & 6000 & 6000 & 6000 \\
VCharging & 2000 & 2000 & 2000 \\
\hline
\end{tabular}

Quantification was achieved through matrix-matched external calibration, using eight concentrations ranging from $0.05 \mu \mathrm{g} \cdot \mathrm{L}^{-1}$ to $1000 \mu \mathrm{g} \cdot \mathrm{L}^{-1}$. Concentrations of the samples were calculated based on the linear regression of the calibration samples and were performed with the software Agilent MassHunter.

Caffeine served as an internal standard. It was used for visual evaluation of extraction and injection, but no correctional factor was calculated. The limit of detection $(L O D)$ was experimentally determined using spiked blank extracts. The LODs (signal to noise 10) for the various pesticides were between 0.04 and $10 \mu \mathrm{g} \cdot \mathrm{L}^{-1}$ corresponding to values between 0.4 and $100 \mu \mathrm{g} \cdot \mathrm{kg}^{-1}$ in wax (Table 4). Since our blank beeswax contained DEET and azoxystrobin, we could not experimentally determine the $L O D s$ for these two pesticides, hence the indication nonapplicable (n.a.). The recoveries for the pesticides were tested at least at five spiking levels with at least five repetitions each. Recoveries of $80-120 \%$ were accepted. The final validated range for all 21 pesticides can be found in Table 4 . The limits of quantification $(L O Q)$ were defined as the lowest validated spike level, where the recoveries were above $80 \%$. The $L O Q s$ for the tested pesticides ranged between 0.5 and $200 \mu \mathrm{g} \cdot \mathrm{kg}^{-1}$ in wax (Table 4). We set the $L O Q$ at levels above the blank values for DEET $\left(20 \mu \mathrm{g} \cdot \mathrm{kg}^{-1}\right)$ and for azoxystrobin $\left(10 \mu \mathrm{g} \cdot \mathrm{kg}^{-1}\right)$ to ensure proper quantification.

The mean and median values for pesticides were calculated across the 98 individual foundation samples, taking values below $L O Q$ as 0 . For some pesticides with only a few quantifiable measurements (boscalid, chlorpyrifos, DMF, flumethrin, permethrin and propoxur), a mean and/ or median below $L O Q$ was obtained.
Table 3 Ion transitions used for quantification and qualification

\begin{tabular}{|c|c|c|c|c|c|c|c|}
\hline \multirow[b]{2}{*}{ Analyte } & \multirow[b]{2}{*}{$\begin{array}{l}\text { Precursor } \\
\text { ion }(\mathrm{m} / \mathrm{z})^{\mathrm{a}}\end{array}$} & \multicolumn{2}{|l|}{ Quantifier } & \multicolumn{2}{|l|}{ Qualifier 1} & \multicolumn{2}{|l|}{ Qualifier 2} \\
\hline & & $\begin{array}{l}\text { Product ion } \\
(\mathrm{m} / \mathrm{z})\end{array}$ & $\begin{array}{l}\mathrm{CE}^{\mathrm{b}} \\
(\mathrm{V})\end{array}$ & $\begin{array}{l}\text { Product ion } \\
(\mathrm{m} / \mathrm{z})\end{array}$ & $\mathrm{CE}(\mathrm{V})$ & Product ion $(\mathrm{m} / \mathrm{z})$ & $\mathrm{CE}(\mathrm{V})$ \\
\hline Acrinathrin & 559.2 & 208.2 & 14 & 181.2 & 38 & 83.2 & 18 \\
\hline Azoxystrobin & 404.1 & 372.3 & 14 & 344.3 & 26 & 329.3 & 34 \\
\hline Bendiocarb & 244.1 & 167.2 & 6 & 109.1 & 18 & 81.2 & 42 \\
\hline Boscalid & 343.0 & 271.3 & 38 & 272.3 & 34 & 140.1 & 18 \\
\hline Bromopropylate & 444.0 & 208.9 & 42 & 408.7 & 6 & 152.9 & 66 \\
\hline Caffeine (IS) & 195.1 & 138.2 & 18 & 110.1 & 26 & 42.3 & 74 \\
\hline Chlorfenvinphos & 359.0 & 155.1 & 10 & 205.1 & 22 & 170.1 & 50 \\
\hline Chlorpyrifos & 349.9 & 198.0 & 18 & 125.1 & 18 & 97.1 & 34 \\
\hline Coumaphos & 363.0 & 226.8 & 30 & 306.7 & 18 & 210.8 & 34 \\
\hline Zeta-cypermethrin & 433.1 & 191.1 & 14 & 416.3 & 6 & 127.1 & 34 \\
\hline DEET & 192.1 & 119.1 & 18 & 91.2 & 34 & 65.2 & 58 \\
\hline Deltamethrin & 521.0 & 279.1 & 14 & 504.1 & 6 & 172.1 & 34 \\
\hline $\mathrm{DMF}$ & 150.1 & 106.9 & 22 & 106.0 & 38 & 77.0 & 50 \\
\hline Fenitrothion & 278.0 & 125.1 & 22 & 246.2 & 18 & 109.1 & 18 \\
\hline (E)-fenpyroximate & 422.2 & 366.4 & 18 & 138.1 & 34 & 135.1 & 34 \\
\hline Flumethrin & 527.1 & 266.8 & 14 & 509.9 & 6 & 238.8 & 22 \\
\hline Flupyradifurone & 289.1 & 126.1 & 22 & 90.1 & 50 & 73.1 & 80 \\
\hline Tau-fluvalinate & 503.1 & 207.9 & 10 & 180.9 & 38 & 151.9 & 80 \\
\hline Permethrin & 408.1 & 183.2 & 6 & 355.3 & 6 & 165.1 & 54 \\
\hline Piperonyl butoxide & 356.2 & 177.2 & 14 & 119.2 & 42 & 91.2 & 62 \\
\hline Propoxur & 210.1 & 111.1 & 14 & 168.2 & 2 & 93.1 & 26 \\
\hline Thiacloprid & 253.0 & 126.1 & 22 & 90.2 & 46 & 73.1 & 78 \\
\hline
\end{tabular}

${ }^{\mathrm{a}}$ Mass/charge ratio of the ion

${ }^{\mathrm{b}}$ Collision energy (volt) 


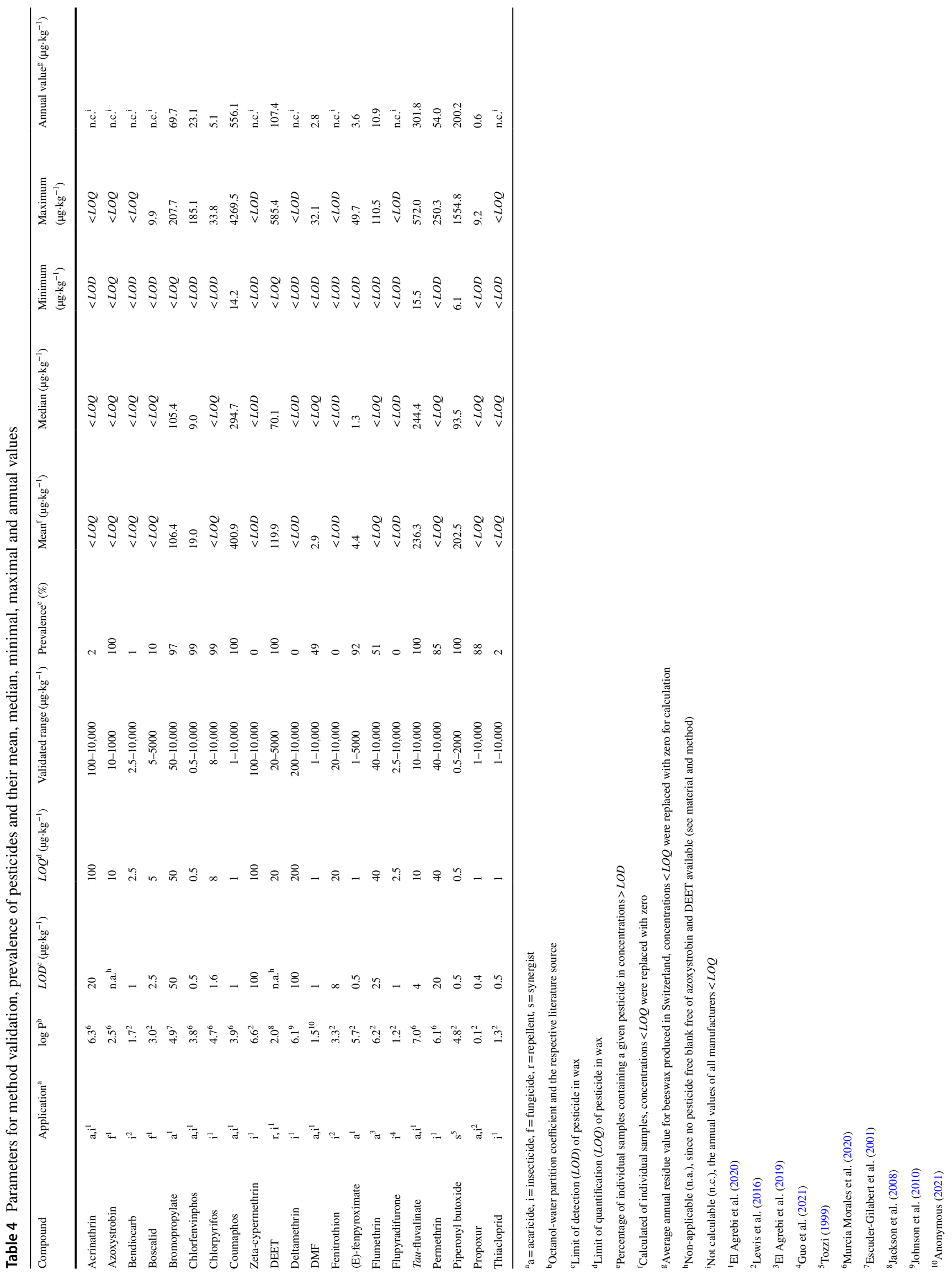




\section{Results}

In total, 17 out of 21 pesticides were detected in the analysed foundation samples, among which 13 pesticides could be quantified (Table 4). The values of mean calculated from the individual samples were similar to the annual residue values (Table 4). The absolute differences ranged from $0.1 \mu \mathrm{g} \cdot \mathrm{kg}^{-1}$ (DMF) to $155 \mu \mathrm{g} \cdot \mathrm{kg}^{-1}$ (coumaphos) (Table 4).

On average, 12 different pesticides were found per sample, with a minimum of seven and a maximum of 14 pesticides per foundation sample. The prevalence of a given pesticide was calculated as the percentage of detections above the $L O D$. The values between the $L O D$ and $L O Q$ were included in this calculation, since information about the presence of the pesticide would otherwise be lost for pesticides with a high $L O Q$ (e.g. Azoxystrobin and DEET were present in the blank wax and thus could not be quantified below 10 and $20 \mu \mathrm{g} \cdot \mathrm{kg}^{-1}$ ). Out of the 21 analysed pesticides, 11 pesticides were found in nearly all the tested foundation samples (85-100\%, Fig. 1). Among them were the beekeeping-associated acaricides coumaphos, tau-fluvalinate and bromopropylate, alongside the insecticides chlorfenvinphos, chlorpyrifos, propoxur and permethrin. Furthermore, the synergist piperonyl butoxide, the fungicide azoxystrobin (however below the $L O Q$ ), the acaricide (E)-fenpyroximate (agricultural use) as well as DEET, a repellent were detected in most samples (Fig. 1). The beekeeping-associated acaricides flumethrin and DMF were detected in approximately $50 \%$ of samples, while the fungicide boscalid was detected in $10 \%$ of the samples (Fig. 1). Additionally, a small number of samples contained one or several of the insecticides acrinathrin, thiacloprid or bendiocarb (Fig. 1). Zeta-cypermethrin, fenitrothion, flupyradifurone and deltamethrin were not detected in the tested foundation samples (Table 4).

The highest mean values were measured for coumaphos $\left(400.9 \mu \mathrm{g} \cdot \mathrm{kg}^{-1}\right)$, tau-fluvalinate $\left(236.3 \mu \mathrm{g} \cdot \mathrm{kg}^{-1}\right)$, piperonyl butoxide $\left(202.5 \mu \mathrm{g} \cdot \mathrm{kg}^{-1}\right)$, DEET $\left(119.9 \mu \mathrm{g} \cdot \mathrm{kg}^{-1}\right)$ and bromopropylate $\left(106.4 \mu \mathrm{g} \cdot \mathrm{kg}^{-1}\right)$ (Table 4). For bromopropylate, tau-fluvalinate and DEET, the mean and median values were similar, while larger deviations between these values were observed for coumaphos and piperonyl butoxide due to some individual samples containing higher residue levels (Table 4). A mean value of $19.0,4.4$ and $2.9 \mu \mathrm{g} \cdot \mathrm{kg}^{-1}$ was obtained for chlorfenvinphos, (E)-fenpyroxymate and DMF, respectively, while the mean values of nine pesticides, namely, acrinathrin, azoxystrobin, bendiocarb, boscalid, chlorpyrifos, flumethrin, permethrin, propoxur and thiacloprid were $<L O Q$.

Residue levels of coumaphos and piperonyl butoxide showed a large variability, with residue levels from 14.2 to $4269.5 \mu \mathrm{g} \cdot \mathrm{kg}^{-1}$ and from 6.1 to $1554.8 \mu \mathrm{g} \cdot \mathrm{kg}^{-1}$, respectively, while residue levels regarding tau-fluvalinate, bromopropylate, DEET and permethrin were more uniformly distributed in the tested foundation samples (Fig. 2).

\section{Discussion}

In total, 17 different pesticides were identified, of which 13 could be quantified. Among these pesticides, 11 were present in the majority of the tested production batches.
Fig. 1 Prevalence of the 21 analysed pesticides in beeswax: The prevalence was calculated as percentage of detections above $L O D$ compared to all 98 individual samples. Light grey bars show the detections $L O D<$ value $<L O Q$, dark grey bars are detections $>L O Q$. The individual limits of detection $(L O D)$ for each pesticide are listed in Table 4

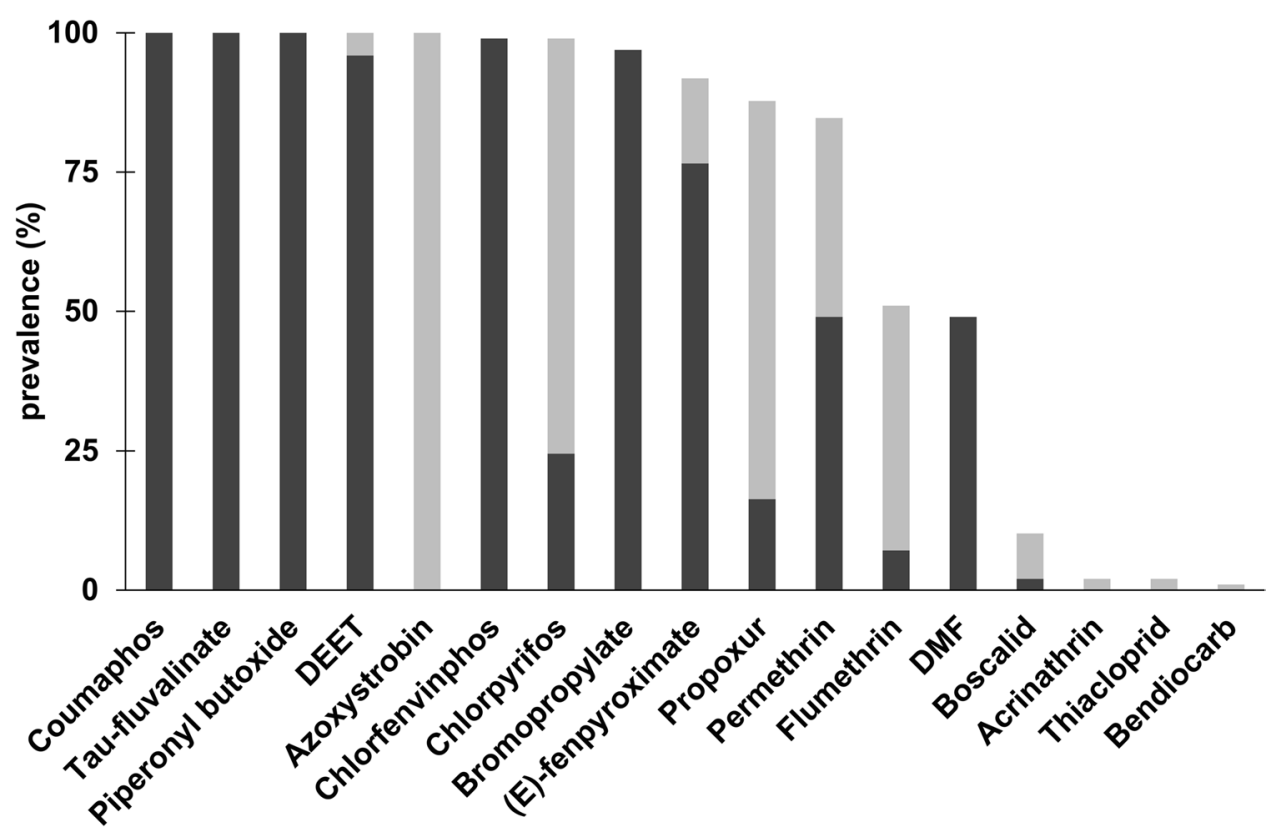


Fig. 2 Box plots for pesticides with the six highest maximums: The line at the centre of each box indicates the median, while the edges of the boxes indicate the upper and lower quartiles. The whiskers contain a distance up to the highest value within 1.5 times the interquartile range. Residue values outside this range are indicated as circles

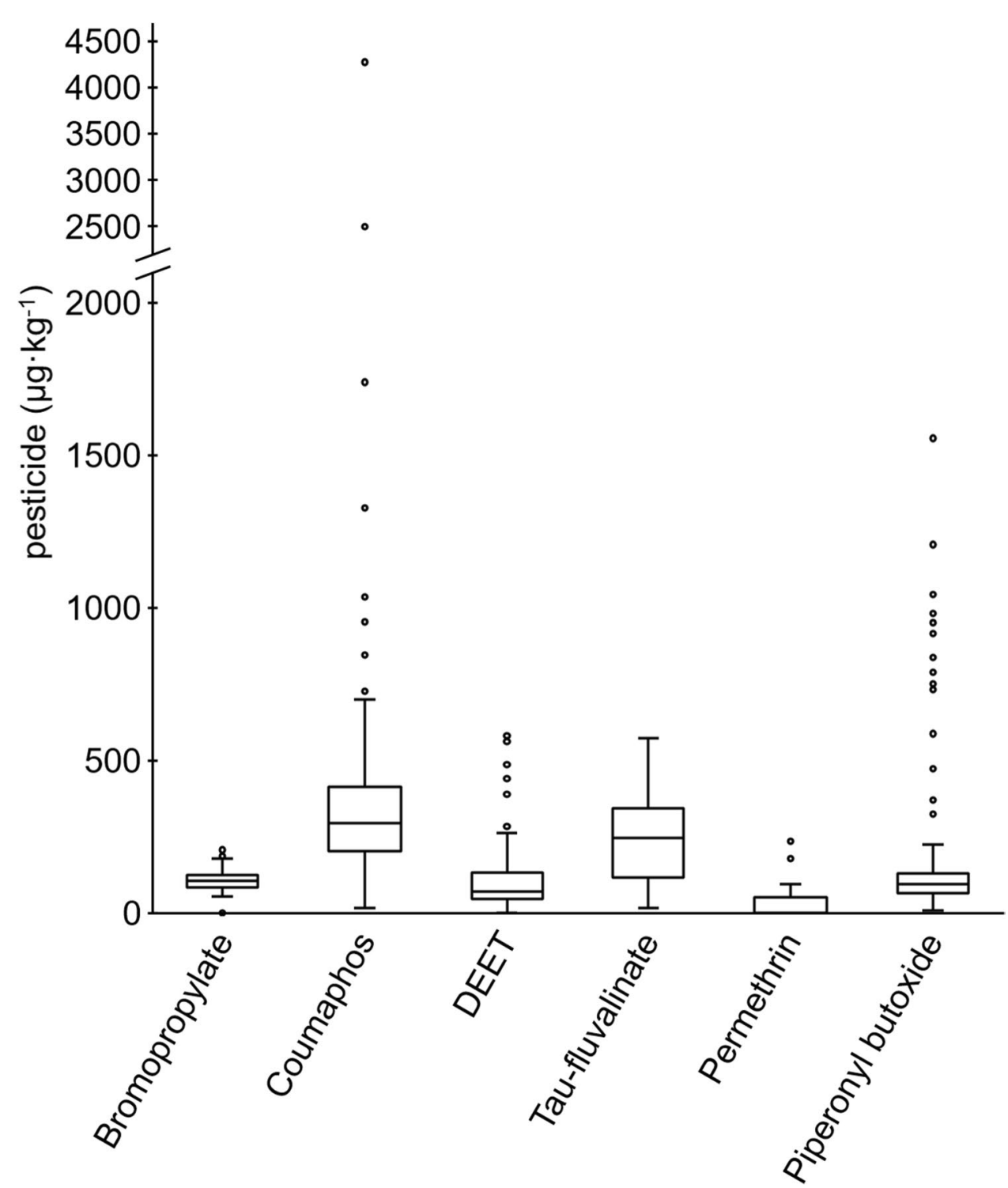

The quantitatively most prominent contaminants were coumaphos and tau-fluvalinate, which are two acaricides with previous authorisation for beekeeping in Switzerland. The highest residue values in individual foundations were obtained for coumaphos, followed by piperonyl butoxide, a synergist frequently applied as part of some plant protection products.

The two different approaches, calculating the annual values from pooled samples and determining the means of individually analysed samples, produced comparable results for most pesticides. The sampling for analysis of individual foundations included nine manufacturers and was spread regularly over the whole year 2009, which was probably a prerequisite. Recently, analysing many individual samples has become more feasible because sample preparation and analytical methods have become less time-consuming.
The results of this study are in line with the numerous previous studies reporting that acaricides, especially coumaphos and tau-fluvalinate, are among the most frequently detected pesticides in beeswax (Bogdanov 2004; Calatayud-Vernich et al. 2017; Fulton et al. 2019; Lozano et al. 2019; Mullin et al. 2010; Perugini et al. 2018; Shimshoni et al. 2019; Spiewok 2017). A product containing coumaphos at a high dose (CheckMite + ) has been authorised in Switzerland for beekeeping (Kast et al. 2020). However, it was rarely used by beekeepers in the last few years (Kast et al. 2021). Its authorisation in Switzerland expired in September 2021. A tau-fluvalinate-containing product was authorised in Switzerland for beekeeping until December 2006 and the residue levels of tau-fluvalinate have decreased since the 2000s (Kast et al. 2021). However, slightly increased values have been observed since 2015 (Kast et al. 2021), possibly due to an import of wax from countries where 
tau-fluvalinate is authorised for beekeeping or as a plant protection product (D'Ascenzi et al. 2019). Furthermore, bromopropylate is still present in $97 \%$ of samples up to a maximal level of $208 \mu \mathrm{g} \cdot \mathrm{kg}^{-1}$, even though the authorisation period in Switzerland ended in 1999 (Kast et al. 2021). Just like tau-fluvalinate, residue levels have been slowly decreasing over time. The three acaricides coumaphos, taufluvalinate and bromopropylate have high octanol-water partition coefficients of 3.9, 7.0 and 4.9 (Escuder-Gilabert et al. 2001; Murcia Morales et al. 2020), respectively. Thus, they have lipophilic character, accumulate preferentially in wax and remain in recycled wax over many years. The use of the more hydrophilic organic acids for mite control instead of lipophilic acaricides can help to keep residue levels in beeswax low.

In this study, mean residue levels were $401 \mu \mathrm{g} \cdot \mathrm{kg}^{-1}$ and $236 \mu \mathrm{g} \cdot \mathrm{kg}^{-1}$ for coumaphos and tau-fluvalinate, respectively. These levels were comparable to the levels measured in the beeswax of neighbouring countries, such as Germany (means of 720 and $230 \mu \mathrm{g} \cdot \mathrm{kg}^{-1}$, Shimshoni et al. 2019), France (means of 648 and $220 \mu \mathrm{g} \cdot \mathrm{kg}^{-1}$, Chauzat et al. 2011) and Italy (in 2014, means of 217 and $130 \mu \mathrm{g} \cdot \mathrm{kg}^{-1}$, Boi et al. 2016). Higher average levels of coumaphos and tau-fluvalinate were reported, for example, in a Spanish study (means of 9486 and $1085 \mu \mathrm{g} \cdot \mathrm{kg}^{-1}$, Calatayud-Vernich et al. 2017) or in a North American study (means of 3300 and $7474 \mu \mathrm{g} \cdot \mathrm{kg}^{-1}$, Mullin et al. 2010). We observed a high variability of coumaphos levels between the batches, with a maximal value of $4270 \mu \mathrm{g} \cdot \mathrm{kg}^{-1}$, which is in the same order of magnitude to maximal values reported for France $\left(4113 \mu \mathrm{g} \cdot \mathrm{kg}^{-1}\right.$, Chauzat et al. 2011) and Germany (10 $900 \mu \mathrm{g} \cdot \mathrm{kg}^{-1}$, Shimshoni et al. 2019). However, the individual batches were more homogeneous regarding tau-fluvalinate residue levels. The maximal value of $572 \mu \mathrm{g} \cdot \mathrm{kg}^{-1}$ is comparable to a maximal level measured in French beeswax (446 $\mu \mathrm{g} \cdot \mathrm{kg}^{-1}$, Chauzat et al. 2011). In contrary, higher maximal residue levels were previously reported in German wax $\left(8500 \mu \mathrm{g} \cdot \mathrm{kg}^{-1}\right.$, Spiewok 2017) although $t a u$-fluvalinate has never been authorised for beekeeping in Germany (Wallner 2014).

Coumaphos levels of up to $20000 \mu \mathrm{g} \mathrm{kg}^{-1}$ in wax were non-lethal to honey bee larvae, as previously shown in an in vitro model (Kast and Kilchenmann 2022), suggesting that the coumaphos levels currently measured in Swiss beeswax or in wax of the neighbouring countries most likely do not affect brood development. Furthermore, a recent study showed that wax foundations containing coumaphos, taufluvalinate and thymol at a concentration of $10000 \mu \mathrm{g} \cdot \mathrm{kg}^{-1}$ each did not increase brood mortality rates (Alkassab et al. 2020). Additional studies on lethal and sub-lethal effects of the various pesticides in beeswax as well as the synergistic effects of a mix of pesticides on honeybees would be helpful to determine maximal residue levels for beeswax.
Coumaphos, tau-fluvalinate and bromopropylate (three out of 21 pesticides described in the current study) have been previously analysed in a long-term survey for Swiss beeswax (Kast et al. 2021). Thus, the pooled samples of the year 2019 (but not the individual samples) have been analysed using two different analytical procedures. In the previous survey, the samples were purified on a florisil column and analysed by gas chromatography (Kast et al. 2021), while in the current study, the samples were extracted with modified QuEChERS procedure and analysed by liquid chromatography. Despite the different extraction procedures, the annual values (year 2019) obtained in the previous study for coumaphos $\left(410 \mu \mathrm{g} \cdot \mathrm{kg}^{-1}\right)$, tau-fluvalinate $\left(380 \mu \mathrm{g} \cdot \mathrm{kg}^{-1}\right)$ and bromopropylate $\left(79 \mu \mathrm{g} \cdot \mathrm{kg}^{-1}\right)$ were comparable to the annual values obtained in this current survey $\left(556,302,70 \mu \mathrm{g} \cdot \mathrm{kg}^{-1}\right)$. A significant advantage of the method described here is the easier sample preparation and the fast chromatographic analysis. Thus, the current method is substantially more cost-effective and allowed the simultaneous analysis of 18 more pesticides.

Flumethrin has been authorised as an acaricide in Switzerland since 1991 and to date. It was detected in $51 \%$ of the analysed samples (>LOD) mostly low levels. In 7\% of the analysed samples, flumethrin could be quantified $(>L O Q$ ). The residue levels (mean $\angle L O Q$ and maximum $\left.111 \mu \mathrm{g} \cdot \mathrm{kg}^{-1}\right)$ were below the levels reported for German (mean $160 \mu \mathrm{g} \cdot \mathrm{kg}^{-1}$, maximum 10,900 $\mu \mathrm{g} \cdot \mathrm{kg}^{-1}$, Shimshoni et al. 2019), Italian (mean $40 \mu \mathrm{g} \cdot \mathrm{kg}^{-1}$, maximum $110 \mu \mathrm{g} \cdot \mathrm{kg}^{-1}$, Perugini et al. 2018) or Spanish wax (mean $91 \mu \mathrm{g} \cdot \mathrm{kg}^{-1}$, maximum $170 \mu \mathrm{g} \cdot \mathrm{kg}^{-1}$, Calatayud-Vernich et al. 2017). This is most likely because $S$ wiss beekeepers rarely used products containing flumethrin (Bogdanov et al. 2002).

Even though amitraz-containing products have never been authorised in Switzerland for beekeeping, $49 \%$ of the foundation batches contained DMF, the breakdown product of amitraz, although at low concentrations. This might be due to the illegal use of amitraz-containing products or due to the import of wax from neighbouring countries, where such products are authorised for mite control (D'Ascenzi et al. 2019).

The insecticides frequently detected in our analysed samples (85-100\%) were chlorfenvinphos, chlorpyrifos, permethrin and propoxur. Plant protection products containing chlorfenvinphos were authorised in Switzerland until 2011, but nowadays no such product is authorised for use in beekeeping or as plant protection. The mean and maximal values of chlorfenvinphos $\left(19 ; 185 \mu \mathrm{g} \cdot \mathrm{kg}^{-1}\right)$ in this study were below the values reported for neighbouring countries, Italy $\left(60 ; 630 \mu \mathrm{g} \cdot \mathrm{kg}^{-1}\right.$, Perugini et al. 2018) and Germany (200; $6400 \mu \mathrm{g} \cdot \mathrm{kg}^{-1}$, Shimshoni et al. 2019). Chlorfenvinphos has been reported at mean and maximal values of 1491 and $5285 \mu \mathrm{g} \cdot \mathrm{kg}^{-1}$ in Spanish wax foundations, suggesting its unauthorised use as an acaricide in 
beekeeping (Calatayud-Vernich et al. 2017). Mean and maximal values of chlorpyrifos $\left(<L O Q ; 34 \mu \mathrm{g} \cdot \mathrm{kg}^{-1}\right)$ in this study were lower than the values reported for German wax $\left(70 ; 1800 \mu \mathrm{g} \cdot \mathrm{kg}^{-1}\right.$, Shimshoni et al. 2019) or North American wax (24; $890 \mu \mathrm{g} \cdot \mathrm{kg}^{-1}$, Mullin et al. 2010). In Switzerland, the approval for plant protection products containing chlorpyrifos was revoked in July 2020 (de Baan et al. 2020). Thus, levels in wax should decrease over the next years. Permethrin and propoxur are not authorised for use as plant protection in Switzerland. While permethrin is still authorised as a biocide for the protection of wood, propoxur is no longer authorised as a biocide in Switzerland (FOEN, FOPH and SECO 2021). The mean and maximal levels (permethrin mean $<L O Q$, maximum $250 \mu \mathrm{g} \cdot \mathrm{kg}^{-1}$; propoxur mean $<L O Q$, maximum $9 \mu \mathrm{g} \cdot \mathrm{kg}^{-1}$ ) are below the recently reported residue levels in German wax (mean 170; maximum $2400 \mu \mathrm{g} \cdot \mathrm{kg}^{-1}$ and mean 10; maximum $30 \mu \mathrm{g} \cdot \mathrm{kg}^{-1}$, respectively, Shimshoni et al. 2019). Levels of permethrin were also higher in North American wax (mean 210; maximum $372 \mu \mathrm{g} \cdot \mathrm{kg}^{-1}$; Mullin et al. 2010). Especially chlorpyrifos and permethrin are highly toxic to adult bees through oral or contact exposure (contact $\mathrm{LD}_{50}: 0.01 \mu \mathrm{g} \cdot \mathrm{bee}^{-1}$; oral $\mathrm{LD}_{50} 0.25 \mu \mathrm{g} \cdot \mathrm{bee}^{-1}$ for chlorpyrifos (Stoner and Eitzer 2013) and contact $\mathrm{LD}_{50} 0.06 \mu \mathrm{g} \cdot \mathrm{bee}^{-1}$; oral $\mathrm{LD}_{50} 0.13 \mu \mathrm{g} \cdot \mathrm{bee}^{-1}$ for permethrin (Sanchez-Bayo and Goka 2014), respectively). Larvae tolerate chlorpyrifos mildly better on oral exposure than adult bees $\left(\mathrm{LD}_{50} 0.46 \mu \mathrm{g} \cdot \mathrm{larva}^{-1}\right.$, Dai et al. 2017). So far, the exposure route through beeswax is not well studied and it is not clear what concentration level in beeswax leads to increased mortality.

Furthermore, the tested samples contained the fungicides azoxystrobin and boscalid, which are widely used in agriculture to protect cultures, such as berry, stone fruits, vegetables and rape (boscalid). Both are currently authorised for use in Switzerland as plant protection products (FOAG 2021).

Several products containing (E)-fenpyroximate as an active ingredient are currently authorised for use in Switzerland (FOAG 2021). (E)-fenpyroximate is an acaricide used, for example, for the protection of grapes, apples, pears and beans (European Food Safety Authority 2013). It was found in $92 \%$ of the tested foundation samples at low levels (mean and maximum concentrations of $4 \mu \mathrm{g} \cdot \mathrm{kg}^{-1}$ and $50 \mu \mathrm{g} \cdot \mathrm{kg}^{-1}$, respectively).

Piperonyl butoxide was found in all the analysed samples, ranging from 6 to $1555 \mu \mathrm{g} \cdot \mathrm{kg}^{-1}$. Similar levels were measured in Italian beeswax (Perugini et al. 2018), while mean values of beeswax from Belgium or Germany were four times lower (El Agrebi et al. 2020; Shimshoni et al. 2019). This substance on its own has low toxicity to mammals (Tozzi 1999), birds and bees (Cross et al. 2017). Instead, it supports the effect of pyrethrum and pyrethroid insecticides, serving as a synergist (Tozzi 1999). Its effect is the prevention of the oxidative enzymatic breakdown of insecticides, mostly by inhibition of cytochrome P450 (Hodgson and Levi 1999). Consequently, the pyrethroid's toxicity is increased, or the same toxicity is achieved at a lower insecticide concentration (Wickham 1999).

DEET was also detected in all the analysed samples, with a mean concentration of $120 \mu \mathrm{g} \cdot \mathrm{kg}^{-1}$ and a maximum value of $585 \mu \mathrm{g} \cdot \mathrm{kg}^{-1}$ at similar levels reported for Germany (maximum $1300 \mu \mathrm{g} \cdot \mathrm{kg}^{-1}$, Wallner 2014) or Belgium (mean $102 \mu \mathrm{g} \cdot \mathrm{kg}^{-1}$; maximum $707 \mu \mathrm{g} \cdot \mathrm{kg}^{-1}$, El Agrebi et al. 2020). Several years ago, this active ingredient was used as a repellent in beekeeping (Wallner 2014). In the meantime, the formulation of such products has been changed and DEET-containing products for beekeeping are no longer on the market. However, DEET is still used as an insect repellent (Ditzen et al. 2008), e. g. in mosquito sprays. Despite its popularity, the mechanism of toxicity in insects, mammals and humans, as well as the effect on the target olfactory system, is still controversial (Corbel et al. 2009). Indeed, an experiment conducted by Corbel et al. (2009) found that DEET has the potential to inhibit cholinesterase on its own and increase the potency of carbamates, a class of insecticides that block acetylcholinesterase.

\section{Conclusion}

The acaricides coumaphos and tau-fluvalinate were the most important residues in Swiss beeswax, followed by the synergist piperonyl butoxide. The residue levels of these two beekeeping-associated acaricides were comparable to the levels reported for wax of the neighbouring countries, while residue levels of piperonyl butoxide were similar to levels in Italian wax, but above the levels measured in wax from Belgium or Germany. On the other hand, the levels of the acaricides flumethrin and DMF, as well as the levels of the insecticides chlorfenvinphos, chlorpyrifos, permethrin and propoxur, were below the levels reported in studies on European wax.

The coumaphos residue levels in Swiss beeswax most likely do not cause lethal brood effects, since the maximal coumaphos level in Swiss wax was seven times below a level that increased brood mortality in an in vitro assay. Additional studies are needed to test brood mortality related to residue levels of a variety of pesticides in beeswax.

Author contribution $\mathrm{CK}$ and VK designed the experiments. VK, CK, JNGM validated the chromatographic method. JNGM performed the analysis of the foundation samples. CK, VK and JNGM interpreted the data. JNGM wrote the paper and CK revised it. All of the authors read and approved the final manuscript.

Funding Open access funding provided by Agroscope. 
Data availability All data generated during this study are included in this article.

\section{Declarations}

Ethics approval and consent to participate Not applicable.

Consent for publication Not applicable.

Competing interests The authors declare no competing interests.

Open Access This article is licensed under a Creative Commons Attribution 4.0 International License, which permits use, sharing, adaptation, distribution and reproduction in any medium or format, as long as you give appropriate credit to the original author(s) and the source, provide a link to the Creative Commons licence, and indicate if changes were made. The images or other third party material in this article are included in the article's Creative Commons licence, unless indicated otherwise in a credit line to the material. If material is not included in the article's Creative Commons licence and your intended use is not permitted by statutory regulation or exceeds the permitted use, you will need to obtain permission directly from the copyright holder. To view a copy of this licence, visit http://creativecommons.org/licenses/by/4.0/.

\section{References}

Alkassab AT, Thorbahn D, Frommberger M, Bischoff G, Pistorius J (2020) Effect of contamination and adulteration of wax foundations on the brood development of honeybees. Apidologie 51:642651. https://doi.org/10.1007/s13592-020-00749-2

Anonymous (2021) PubChem Compound Summary for CID 92363 , N-(2,4-Dimethylphenyl)formamide. National Center for Biotechnology Information https://pubchem.ncbi.nlm.nih.gov/compound/ 92363

Bogdanov S, Kilchenmann V, Imdorf A (1998) Acaricide residues in some bee products. J Apic Res 37:57-67. https://doi.org/10.1080/ 00218839.1998.11100956

Bogdanov S, Imdorf A, Charrière JD, Fluri P, Kilchenmann V (2002) Qualität der Bienenprodukte und die Verschmutzungsquellen. Teil 2: Belastung aus der Imkerei. Schweiz Bienenztg 125:22-27

Bogdanov S (2004) Beeswax: quality issues today. Bee World 85:4650. https://doi.org/10.1080/0005772X.2004.11099623

Boi M, Serra G, Colombo R, Lodesani M, Massi S, Costa C (2016) A 10 year survey of acaricide residues in beeswax analysed in Italy. Pest Manag Sci 72:1366-1372. https://doi.org/10.1002/ps.4161

Calatayud-Vernich P, Calatayud F, Simó E, Picó Y (2017) Occurrence of pesticide residues in Spanish beeswax. Sci Total Environ 605606:745-754. https://doi.org/10.1016/j.scitotenv.2017.06.174

Chauzat M-P, Martel A-C, Cougoule N, Porta P, Lachaize J, Zeggane S, Aubert M, Carpentier P, Faucon J-P (2011) An assessment of honeybee colony matrices, Apis mellifera (Hymenoptera: Apidae) to monitor pesticide presence in continental France. Environ Toxicol Chem 30:103-111. https://doi.org/10.1002/etc.361

Corbel V, Stankiewicz M, Pennetier C, Fournier D, Stojan J, Girard E, Dimitrov M, Molgó J, Hougard J-M, Lapied B (2009) Evidence for inhibition of cholinesterases in insect and mammalian nervous systems by the insect repellent deet. BMC Biol 7:47. https://doi. org/10.1186/1741-7007-7-47

Cross A, Bond C, Buhl K, Jenkins J (2017) Piperonyl Butoxide (PBO) General Fact Sheet. National Pesticide Information Center,
Oregon State University Extension Services http://npic.orst.edu/ factsheets/pbogen.html

D’Ascenzi C, Formato G, Martin P (2019) Chemical hazards in honey. In: Smulders FJM, Rietjens IMCM, Rose MD (Eds), Food safety assurance and veterinary public health, Chemical hazards in foods of animal origin, vol.7, $1^{\text {st }}$ edn. Wageningen Academic Publishers, Wageningen, 443-475

Dai P, Jack CJ, Mortensen AN, Ellis JD (2017) Acute toxicity of five pesticides to Apis mellifera larvae reared in vitro. Pest Manag Sci 73:2282-2286. https://doi.org/10.1002/ps.4608

de Baan L., Blom J, Daniel O (2020) Pflanzenschutzmittel im Feldbau: Einsatz und Gewässerrisiken von 2009 bis 2018. Agrarforschung Schweiz 11:162-174. https://doi.org/10.34776/afs11-162g

Ditzen M, Pellegrino M, Vosshall LB (2008) Insect odorant receptors are molecular targets of the insect repellent DEET. Science 319:1838. https://doi.org/10.1126/science.1153121

El Agrebi N, Wilmart O, Urbain B, Danneels EL, de Graaf DC, Saegerman C (2019) Belgian case study on flumethrin residues in beeswax: possible impact on honeybee and prediction of the maximum daily intake for consumers. Sci Total Environ 687:712-719. https://doi.org/10.1016/j.scitotenv.2019.05.493

El Agrebi N, Traynor K, Wilmart O, Tosi S, Leinartz L, Danneels E, de Graaf DC, Saegerman C (2020) Pesticide and veterinary drug residues in Belgian beeswax: occurrence, toxicity, and risk to honey bees. Sci Total Environ 745:141036. https://doi.org/10. 1016/j.scitotenv.2020.141036

FOAG (Federal Office for Agriculture) (2021) Plant protection product directory version of 10.12.2021. https://www.psm.admin.ch

FOEN (Federal Office for the Environment), FOPH (the Federal Office of Public Health) and SECO (the State Secretariat for Economic Affairs) (2021) The Notification Authority for chemicals: Annex 2 OBP - Union list of approved active substances, version of 7.10.2021

Escuder-Gilabert L, Martín-Biosca Y, Sagrado S, Villanueva-Camañas RM, Medina-Hernández MJ (2001) Biopartitioning micellar chromatography to predict ecotoxicity. Anal Chim Acta 448:173-185. https://doi.org/10.1016/S0003-2670(01)01320-4

European Food Safety Authority (EFSA) (2013) Conclusion on the peer review of the pesticide risk assessment of the active substance fenpyroximate. EFSA J 11:3493. https://doi.org/10.2903/j. efsa.2013.3493

Fulton CA, Huff Hartz KE, Fell RD, Brewster CC, Reeve JD, Lydy MJ (2019) An assessment of pesticide exposures and land use of honey bees in Virginia. Chemosphere 222:489-493. https://doi. org/10.1016/j.chemosphere.2019.01.156

Guo Y, Diao Q-Y, Dai P-L, Wang Q, Hou C-S, Liu Y-J, Zhang L, Luo Q-H, Wu Y-Y, Gao J (2021) The effects of exposure to flupyradifurone on survival, development, and foraging activity of honey bees (Apis mellifera L.) under field conditions. Insects 12:357. https://doi.org/10.3390/insects 12040357

Hodgson E, Levi PE (1999) 3 - Interactions of piperonyl butoxide with cytochrome P450. In: Jones DG (ed) piperonyl butoxide. Academic Press, London, pp 41-II. https://doi.org/10.1016/B978012286975-4/50005-X

Jackson D, Luukinen B, Buhl K, Stone D (2008) DEET technical fact sheet. National Pesticide Information Center, Oregon State University Extension Services http://npic.orst.edu/factsheets/archive/ DEETtech.html

Johnson M, Luukinen B, Buhl K, Stone D (2010) Deltamethrin technical fact sheet. National Pesticide Information Center, Oregon State University Extension Services http://npic.orst.edu/factsheets/archi ve/Deltatech.html

Kast C, Kilchenmann V, Droz B (2020) Distribution of coumaphos in beeswax after treatment of honeybee colonies with CheckMite ${ }^{\circledR}$ 
against the parasitical mite Varroa destructor. Apidologie 51:112122. https://doi.org/10.1007/s13592-019-00724-6

Kast C, Kilchenmann V, Charrière J-D (2021) Long-term monitoring of lipophilic acaricide residues in commercial Swiss beeswax. Pest Manage Sci 77:4026-4033. https://doi.org/10.1002/ps.6427

Kast C, Kilchenmann V (2022) An in vitro model for assessing the toxicity of pesticides in beeswax on honey bee larvae. Chemosphere 287(2):132214. https://doi.org/10.1016/j.chemosphere. 2021.132214

Lewis KA, Tzilivakis J, Warner DJ, Green A (2016) An international database for pesticide risk assessments and management. Hum Ecol Risk Assess 22:1050-1064. https://sitem.herts.ac.uk/aeru/ ppdb. https://doi.org/10.1080/10807039.2015.1133242

Lozano A, Hernando MD, Uclés S, Hakme E, Fernández-Alba AR (2019) Identification and measurement of veterinary drug residues in beehive products. Food Chem 274:61-70. https://doi.org/10. 1016/j.foodchem.2018.08.055

Martel A-C, Zeggane S, Aurières C, Drajnudel P, Faucon J-P, Aubert M (2007) Acaricide residues in honey and wax after treatment of honey bee colonies with Apivar ${ }^{\circledR}$ or Asuntol $^{\circledR} 50$. Apidologie 38:534-544. https://doi.org/10.1051/apido:2007038

Martinello M, Manzinello C, Borin A, Avram LE, Dainese N, Giuliato I, Gallina A, Mutinelli F (2020) A survey from 2015 to 2019 to investigate the occurrence of pesticide residues in dead honeybees and other matrices related to honeybee mortality incidents in Italy. Diversity 12:15. https://doi.org/10.3390/d12010015

Mullin CA, Frazier M, Frazier JL, Ashcraft S, Simonds R, vanEngelsdorp D, Pettis JS (2010) High levels of miticides and agrochemicals in North American apiaries: implications for honey bee health. PLoS ONE 5:e9754. https://doi.org/10.1371/journal.pone. 0009754

Murcia Morales M, Gómez Ramos MJ, Parrilla Vázquez P, Díaz Galiano FJ, García Valverde M, Gámiz López V, Manuel Flores J, Fernández-Alba AR (2020) Distribution of chemical residues in the beehive compartments and their transfer to the honeybee brood. Sci Total Environ 710:136288. https://doi.org/10.1016/j. scitotenv.2019.136288

Perugini M, Tulini SMR, Zezza D, Fenucci S, Conte A, Amorena M (2018) Occurrence of agrochemical residues in beeswax samples collected in Italy during 2013-2015. Sci Total Environ 625:470476. https://doi.org/10.1016/j.scitotenv.2017.12.321

Rosenkranz P, Aumeier P, Ziegelmann B (2010) Biology and control of Varroa destructor. J Invertebr Pathol 103:S96-S119. https:// doi.org/10.1016/j.jip.2009.07.016
Sanchez-Bayo F, Goka K (2014) Pesticide residues and bees - a risk assessment. PLoS ONE 9:e94482. https://doi.org/10.1371/journ al.pone.0094482

Shimshoni JA, Sperling R, Massarwa M, Chen Y, Bommuraj V, Borisover M, Barel S (2019) Pesticide distribution and depletion kinetic determination in honey and beeswax: model for pesticide occurrence and distribution in beehive products. PLoS ONE 14:e0212631. https://doi.org/10.1371/journal.pone.0212631

Spiewok S (2017) Mittelwände im Test. Das Ergebnis unserer Marktbeprobung. Dtsch Bienen J 25(9): 6-8

Steinhauer N, Kulhanek K, Antúnez K, Human H, Chantawannakul P, Chauzat M-P, vanEngelsdorp D (2018) Drivers of colony losses. Curr Opin Insect Sci 26:142-148. https://doi.org/10.1016/j.cois. 2018.02.004

Stoner KA, Eitzer BD (2013) Using a hazard quotient to evaluate pesticide residues detected in pollen trapped from honey bees (Apis mellifera) in Connecticut. PLoS ONE 8:e77550. https://doi.org/ 10.1371/journal.pone. 0077550

Tozzi A (1999) A brief history of the development of piperonyl butoxide as an insecticide synergist. In: Jones DG (ed) piperonyl butoxide. Academic Press, London, pp 1-5. https://doi.org/10.1016/ B978-012286975-4/50003-6

Wallner K (1999) Varroacides and their residues in bee products. Apidologie 30:235-248. https://doi.org/10.1051/apido:19990 212

Wallner K (2014) Wachs vergisst nicht. Allg Dtsch Imkerztg $12: 10-12$

Wickham JC (1999) The use of synergized pyrethroids to control insect pests in and around domestic, industrial and food-handling premises. In: Jones DG (ed) Piperonyl Butoxide. Academic Press, London, pp 239-260. https://doi.org/10.1016/B978-012286975-4/ 50017-6

Wilmart O, Legrève A, Scippo ML, Reybroeck W, Urbain B, de Graaf DC, Spanoghe P, Delahaut P, Saegerman C (2021) Honey bee exposure scenarios to selected residues through contaminated beeswax. Sci Total Environ 772:145533. https://doi.org/10.1016/j. scitotenv.2021.145533

Wu JY, Anelli CM, Sheppard WS (2011) Sub-lethal effects of pesticide residues in brood comb on worker honey bee (Apis mellifera) development and longevity. PLoS ONE 6:e14720. https://doi.org/ 10.1371/journal.pone.0014720

Publisher's note Springer Nature remains neutral with regard to jurisdictional claims in published maps and institutional affiliations. 